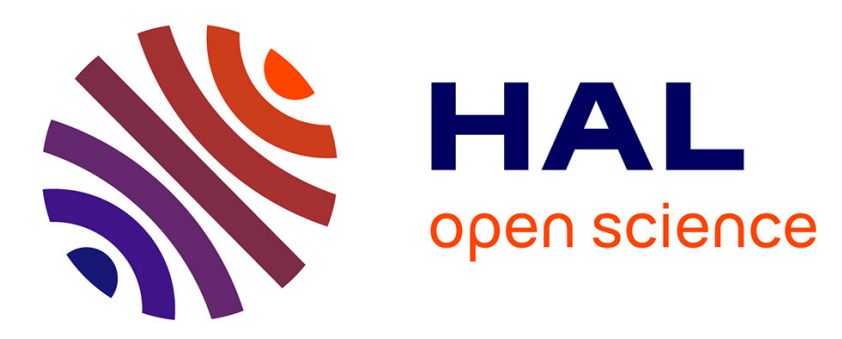

\title{
The use of coarser taxonomy in the detection of long-term changes in polychaete assemblages
}

Luigi Musco, Barbara Mikac, Mariella Tataranni, Adriana Giangrande, Antonio Terlizzi

\section{- To cite this version:}

Luigi Musco, Barbara Mikac, Mariella Tataranni, Adriana Giangrande, Antonio Terlizzi. The use of coarser taxonomy in the detection of long-term changes in polychaete assemblages. Marine Environmental Research, 2011, 71 (2), pp.131. 10.1016/j.marenvres.2010.12.004 . hal-00664017

\section{HAL Id: hal-00664017 https://hal.science/hal-00664017}

Submitted on 28 Jan 2012

HAL is a multi-disciplinary open access archive for the deposit and dissemination of scientific research documents, whether they are published or not. The documents may come from teaching and research institutions in France or abroad, or from public or private research centers.
L'archive ouverte pluridisciplinaire HAL, est destinée au dépôt et à la diffusion de documents scientifiques de niveau recherche, publiés ou non, émanant des établissements d'enseignement et de recherche français ou étrangers, des laboratoires publics ou privés. 


\section{Accepted Manuscript}

Title: The use of coarser taxonomy in the detection of long-term changes in polychaete assemblages

Authors: Luigi Musco, Barbara Mikac, Mariella Tataranni, Adriana Giangrande, Antonio Terlizzi

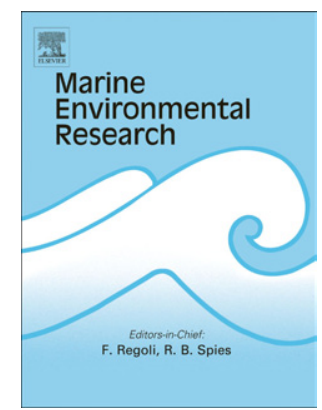

PII: S0141-1136(10)00179-0

DOI: 10.1016/j.marenvres.2010.12.004

Reference: MERE 3492

To appear in: Marine Environmental Research

Received Date: 2 November 2010

Revised Date: 6 December 2010

Accepted Date: 8 December 2010

Please cite this article as: Musco, L., Mikac, B., Tataranni, M., Giangrande, A., Terlizzi, A. The use of coarser taxonomy in the detection of long-term changes in polychaete assemblages, Marine Environmental Research (2010), doi: 10.1016/j.marenvres.2010.12.004

This is a PDF file of an unedited manuscript that has been accepted for publication. As a service to our customers we are providing this early version of the manuscript. The manuscript will undergo copyediting, typesetting, and review of the resulting proof before it is published in its final form. Please note that during the production process errors may be discovered which could affect the content, and all legal disclaimers that apply to the journal pertain. 
The use of coarser taxonomy in the detection of long-term changes in polychaete assemblages

LUIGI MUSCO $^{\mathrm{a},{ }^{*},}$ BARBARA MIKAC $^{\mathrm{b}}$, MARIELLA TATARANNI ${ }^{\mathrm{a}}$, ADRIANA

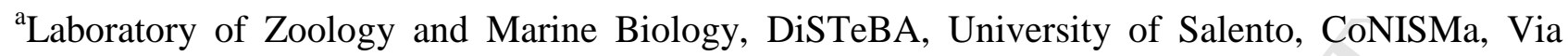
Provinciale Lecce-Monteroni, 73100 Lecce, Italy

${ }^{\mathrm{b}}$ Center for Marine Research, Ruđer Bošković Institute, G. Paliaga 5, 52210 Rovinj, Croatia

9

*Corresponding author. Tel.: +39 0832 298897; fax: +39 0832 298626. E-mail address: luigi.musco@unisalento.it (L. Musco).

\section{ABSTRACT}

Taxonomic Sufficiency (TS) has been proposed as a short-cut method to quantify changes of biological assemblages in environmental monitoring. However, issues about the efficacy of taxonomic surrogates in depicting long-term temporal patterns of marine assemblages are still scant. Here we report on the adoption of TS combined with data transformations to describe patterns of North Adriatic polychaete assemblages through 20 years. Univariate and multivariate analyses revealed large spatial-temporal variation charactering the assemblages. The efficiency to discriminate between the two research periods (1990-1994 vs. 2004-2008) was reduced when data were analyzed at family and order level leading to misinterpreting the sources of assemblage variation. Further information was lost with data transforms. Families may represent appropriate assemblages' descriptors in long-term monitoring, but using TS coupled with data transformations could lead to hazardous loss of information. We suggest that periodical analysis at fine taxonomic level should be routinely alternated to long-term monitoring based on TS in order to check its effectiveness.

Keywords: Taxonomic sufficiency, biomonitoring, Polychaetes, anoxia, temporal variability, taxonomy, Adriatic Sea

\section{INTRODUCTION}


Assessing long-term changes in natural systems (i.e. recovery after mass mortality, effects of restoration or protection, climate change etc.) is one of the most intriguing challenges for quantitative ecology.

In marine environments, measuring patterns of variation in benthic assemblages can provide the most useful information for interpreting the ecological consequences of disturbances and furnish the basis for understanding environmental changes (Underwood, 1996; Underwood and Peterson, 1988). In this context, the benthic macrofauna is particularly suitable for monitoring environmental long-term changes at the ecosystem level (Kroncke, 1995).

Describing assemblages at the highest levels of taxonomic resolution (species) is logistically difficult due to high cost in processing samples and, above all, lack of taxonomic expertise. The development of fast and cost-effective procedures in impact assessment and monitoring studies has become a pressing issue for marine ecologists (Bowen and Depledge, 2006; Ugland et al., 2008). In such context, Taxonomic Sufficiency (TS) (Ellis, 1985), which implies "identifying organisms only to a level of taxonomic resolution sufficient to satisfy the objective of a study" (Bertrand et al., 2006), has been proposed as the ideal compromise procedure in environmental monitoring. TS is supported by evidences that impacts could be detected using coarser taxonomic resolution since abundance/diversity of species are usually related to abundance/diversity of the same organisms identified to supra-specific taxonomic levels (Genus, Family, Order etc.) (e.g. Balmford et al., 1996). It has also been suggested that higher taxa may reflect the effect of anthropogenic disturbance even better than species, being the latter more sensitive to the confounding influence of natural environmental variations (Warwick, 1988; Vanderklift et al., 1996). In general, no significant losses of information, as well as time and costs savings, are the argumentations supporting the TS method in environmental impact assessment (Dauvin et al., 2003, 2010; Herman and Heip, 1988; Munari et al., 2010).

Currently, lacking a general theory on TS, reasons at the base of the effectiveness of TS are still far to be clarified (Dethier and Schoch, 2006). Understanding at which extent functional redundancy overlap taxonomic relatedness of species, would help to provide a general framework on the application of TS in marine systems (Bevilacqua et al., 2009). The need to broaden the array of study cases on the application of TS has been repeatedly stressed (e.g., Bates et al., 2007; Olsgard and Somerfield, 2000; Quijón and Snelgrove, 2006; Terlizzi et al., 2003), because possible biases of TS are to be further investigated. The significance of the Linnaean ranks is being criticized so far as the treatment of same taxonomic ranks as equivalent units is suspected to allow to spurious comparisons (see Bertrand et al., 2006). The extent to which TS affects the results depends on the distribution of species amongst higher taxa in the original samples, that, in turn depends on habitat 
type and bio-geographic background (Musco et al., 2009; Terlizzi et al., 2009). Further, the relation among TS, and data transformation is far to be fully clarified. Several studies showed that transforming data might influence the results of analyses as well as taxonomic aggregation, suggesting that the use of TS coupled with strong transformations of data could lead to severe loss of information (Lasiak, 2003; Olsgard et al., 1998; Wlodarska-Kuwalczuk and Kedra, 2007).

As far as long-term monitoring studies are concerned, the use of coarser taxonomic level, being time-efficient, could improve monitoring programs allowing the extension to additional sampling dates (Thompson et al., 2003; Tataranni et al., 2009). Some loss of information on community structure is considered acceptable for extensive monitoring purposes, and the detection of biodiversity changes should be admissible as well (Bertasi et al., 2009). However, studying the long-term recovery pattern of polychaete assemblages of Botany Bay (NSW, Australia), Fraser et al. (2006) found that the importance of differences in assemblage structure, as well as patterns of succession, could not have been examined in detail using TS. The same Authors suggest that analysis of data at various taxonomic levels, after identification of organisms to species, should be encouraged in long-term impact-assessment studies. This issue, however, is made difficult by the lack of long-term monitoring programmes based on the description of variables at species level. The present study is an attempt in this direction.

Polychaetes are widely distributed, abundant and diverse in terms of species richness and ecological requirements and have been successfully used as indicator taxon (Giangrande et al., 2004, 2005; Musco and Giangrande, 2005; Fraschetti et al., 2006; Musco et al., 2009) also in long-term monitoring studies (Fraser et al., 2006; Schirosi et al., 2010). Here, we compared the effects of taxonomic aggregation and data transformation on the analysis of multivariate patterns of variations related to the decadal changes of the polychaete assemblages, following mass mortality caused by the oxygen depletion in the Northern Adriatic Sea in 1989.

\section{Materials and Methods}

\subsection{Research area}

The Northern Adriatic Sea (hereafter NA) is a semi-enclosed shallow basin exposed to severe human impacts such as strong urban development, high nutrients load, commercial fisheries and different kinds of pollution (Degobbis et al., 2000). Sometimes, when mucilage events coincide with specific hydrographical conditions, anoxia may affect the sea bottom. Such an event happened in the autumn 1989 and caused benthic mass mortality over an area of about $1.200 \mathrm{~km}^{2}$. 
The study was carried out on three offshore monitoring stations of the Centre for Marine Research (Ruđer Bošković Institute, Rovinj) located within the affected area. Station SJ 005 (hereafter 005)

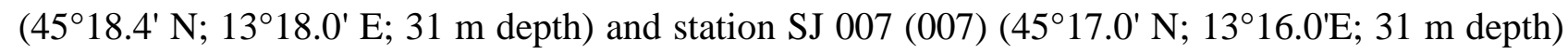
are situated on the profile Poreč (Croatia) - Venice-Lido (Italy), 17 and 13 NM off from the coast of Istrian peninsula (Croatia), respectively. Station SJ 107 (hereafter 107) (4502.8 N; 13¹9.0' E; 37 m depth) is situated on the profile Rovinj (Croatia) - river Po delta, 13 NM off the Istrian coast (Fig. 1). Granulometric analyses showed high similarity in sedimental composition among the three stations. Sediment is weakly sorted silty sand composed mainly by sand (ranging $66.3-70.6 \%$ ), followed by silt and clay fraction $(27.8-32.1 \%)$ and gravel $(1.4-1.6 \%)$.

\subsection{Field and laboratory work}

Starting one year after the anoxia event, samples were taken once a year, in two phases during 1990-1994 and 2004-2008, in the period from late October to the beginning of January .

At each station 4-5 replicates were collected with $0.1 \mathrm{~m}^{2}$ Van-Veen grab, sieved through $2 \mathrm{~mm}$ mesh in the first research period (1990-1994) and 1 and $2 \mathrm{~mm}$ mesh in the second one (2004-2008), and fixed in $4 \%$ buffered formaldehyde-seawater solution. As a whole, 113 samples were collected. The $1 \mathrm{~mm}$ mesh size in the second period was adopted following the up-to-date recommendation for the macrobenthic fauna monitoring studies provided by Castelli et al. (2003). However, for the present study, in order to allow long-term comparisons, only $2 \mathrm{~mm}$ mesh size samples were used. In the laboratory the material was rinsed and macrobenthic organisms sorted and conserved in $70 \%$ ethanol. Polychaetes were determined to the species level using the stereomicroscope and light microscope. Nomenclature followed Castelli et al. (2008).

\subsection{Data Analysis}

Three separate analyses of variances (ANOVAs) were performed to test the null hypotheses of no differences among polychaete assemblages in number of individuals, species richness and Simpson diversity index. The experimental design included three factors: Period (Pe, a fixed factor with 2 levels), Time (T, random, with 9 levels and nested in $\mathrm{Pe}$ ) and Station (S, random, with 3 levels and crossed to both Pe and T).

The same sampling design was used, in the multivariate context, to perform a distance-based permutational multivariate analysis of variance (PERMANOVA) (Anderson, 2001), which used 999 random permutations of appropriate units to test for differences in the polychaetes assemblages' structure among periods across the three stations. The analysis was based on untransformed data at species level. In order to quantify the variability associated with each examined scale, mean squares 
calculated by PERMANOVA were equated to the expected mean squares, like in the univariate case (Benedetti Cecchi, 2001; Searle et al., 1992). For graphical comparisons, the variability at each scale was expressed as a proportion of the total variation (Terlizzi et al., 2007). The same analyses were then repeated for the dataset lumped at genus, family and order taxonomic level.

PERMANOVAs were also carried out for calculating estimates of variance components using $2^{\text {nd }}$ root, $4^{\text {th }}$ root and presence/absence transformed data for all the taxonomic levels investigated.

Non-metric multidimensional scaling ordination plots (MDS) were produced to visualize multivariate patterns of polychaete assemblages classified at species, genus, family and order taxonomic rank. All plots were based on Bray Curtis similarity matrix of untransformed data.

A similarity percentage (SIMPER) routine was performed to detect the species most responsible for differences in the multivariate structure of assemblages between periods.

A second-stage nMDS ordination was also plotted to visualize differences among similarity matrices at different levels of taxonomic aggregation and data transformation (Somerfield and Clarke, 1995).

All multivariate analyses were performed using the computer program PRIMER v6 (Clarke and Gorley, 2006), including the add-on package PERMANOVA+ (Anderson et al., 2008).

\section{Results}

\subsection{Faunal composition}

A total of 5680 polychaete specimens belonging to 173 species, 115 genera, 35 families and 14 orders were collected: among them, 2941 individuals (belonging to 94 species, 67 genera, 29 families and 12 orders) were collected during the first period (1990-1994), and 2739 (130 species, 95 genera, 35 families and 14 orders) during the second one (2004-2008).

As far as the species abundances are concerned, during the first period Owenia fusiformis ranked first (21.2\% of the individuals) followed by Pectinaria auricoma (15.4\%), Eunice vittata (13.1\%) and Nothria conchilega $(10 \%)$. No other species exceeded the $5 \%$ of the total abundance. During the second period $O$. fusiformis remained the most abundant species (10.7\%), but 3 species showed similar abundances, namely Ampharete acutifrons (10.1 \%) (not recorded during 1990-1994), Notomastus latericeus (9.9\%) and P. auricoma (9.7\%). Among the other species only Galathowenia oculata (6.6\%) exceeded the $5 \%$ of the total abundance. As a whole, 39 singletons (i.e. species represented by a single individual) were recorded, among them 12 during the first period ( 1 at station 005, 4 at 007, 7 at 107) and 17 during the second one (6 at station 005, 9 at 007 , 12 at 107). Considering the genera, 24 were singletons, among them 9 during the first period ( 3 at 
007, 6 at 107) and 15 during the second one (1 at station 005, 7 at 007,7 at 107). No singleton families and orders were observed.

The distribution of individuals was variable during the first period (1990-1994) both considering the three stations and the four sampling times (Fig. 2); a lesser degree of variation was visible during the second period (2004-2008). The species richness (Fig. 2) was generally the lowest at the station 5 during the first period and particularly variable during time 2 (period 1) at stations 7 and 107; during the second period, the species richness showed a temporal trend variable within each station but quite similar among stations. The Simpson diversity index (Fig. 2) showed similar trends at all stations; this index appeared more variable, tending to increase from time 1 to time 4 during the first period, while it appeared more homogeneous among times and stations during the second one.

The ANOVA test (Table 1) confirmed the high degree of spatial and temporal variation of the polychaete abundance at the 3 stations during the two analyzed periods; particularly, the significance of the $\mathrm{T}(\mathrm{Pe}) \times \mathrm{St}$ interaction term in the analysis of the number of individuals, revealed that the polychaete abundance varied among times depending on the considered station without a clear pattern between the two considered periods. The test for the species richness indicated significant differences among times and stations, but no difference between periods. The analyses of Simpson diversity revealed significant differences between the polychaete assemblages sampled during 1990-1994 and those sampled during 2004-2008; the test also indicated significant differences among times and stations.

\subsection{Multivariate Analyses}

The results of the MDS analyses carried out on the untransformed abundance species matrix and on matrices derived from the aggregation of species distributions to genus, family and order levels are shown in Figure 3. The plot relative to the polychaete assemblages analyzed at species level (Fig. 3a) showed that centroids representing the 5 times for each of the 3 station sampled during 20042008 (full triangles on the right) formed a group apart from those representing the 4 times for the same stations for the period 1990-1994, thus confirming differences between periods already observed for the univariate indices (Table 1). Almost identical positions of the centroids in the plot were observed using the genera as surrogates of the species (Fig. 3b). The multivariate pattern remained clearly visible when the polychaete assemblage was analyzed at family (Fig. 3c) and order level (Fig. 3d), although the separation between periods became less evident.

The species contributing to the $70 \%$ dissimilarity between the two periods (Average dissimilarity 79.82), and their average abundance in both periods are shown in Table 2 (SIMPER test). The species mostly contributing to differentiate the two periods were also the species dominating the 
assemblages (see 3.1). Interestingly, among the co-familial species only those belonging to

2 Flabelligeridae (2 species) and Pectinariidae (2) showed similar trend of average abundance

3 between the two periods, while species belonging to Onuphidae (3), Oweniidae (2), Spionidae (2) and Ampharetidae (2) showed opposite temporal trends.

5 Table 3 shows the outcomes of the PERMANOVA tests carried out on the original, untransformed species matrix and on matrices derived from the aggregation of species distributions to genus, family and order level. A large degree of variation characterized the polychaete assemblages at all the considered taxonomic levels. The four tests indicate the significance of the $\mathrm{T}(\mathrm{Pe}) \times \mathrm{St}$ interaction term revealing that, whatever the analyzed taxonomic level, the polychaete assemblages varied among times depending on the considered station without a clear pattern, even between periods.

12 Considering the estimate of the variance components (Table 3) however, some difference characterized the analyzed datasets: apart from the residuals, the major source of variation belonged to the factor period for the assemblages analyzed at species and genus level, while for the same assemblages analyzed at family and order level the major source of variation belonged to the $\mathrm{T}(\mathrm{Pe})$ $\times$ St interaction term. Also, the total variation appeared to decrease with the increasing taxonomic level; this pattern was particularly evident when the assemblages were analyzed at family and order level.

Figure 4 compares the relative estimates of the variance components of the untransformed datasets (species, genus, family and order) (Fig. 4a), to those obtained after square-root (Fig. 4b), fourth-root (Fig. 4c) and presence/absence (Fig. 4d) data transform. In every case, the largest variation was among replicate units (i.e. Residual term), while, apart from the analysis of the untransformed datasets at family and order level, the second largest source of variation was always associated to the factor period whatever the taxonomic level and the data transformation used. The ordination of similarity matrices in the second-stage nMDS plot (Fig. 5) showed a typical 'fan' pattern, with a vertical and horizontal spread of points at increasing data transformation and taxonomic aggregation respectively, indicating independent effects of transformations and taxonomic resolution. The effect of taxonomic resolution was particularly evident moving from genus to family level, while the effect of data transformation was already noticeable using the weakest $2^{\text {nd }}$ root transformation because the similarity matrix based on untransformed data fall apart from those obtained by data transformation independently from the taxonomic level considered. In general, within the matrices relative to the same taxonomic rank, those derived from each transformation tend to cluster apart from the similarity matrix obtained by untransformed data. 


\section{Discussion}

As well summarized by the univariate indices, a large and significant degree of variation characterizes the analyzed polychaete assemblages both spatially, at the three stations, and temporally, considering the two analyzed time scales.

Differences between the two periods were visible by the nMDS plot relative to the species showing separation among the centroids representing the assemblages sampled during the 1990-1994 post anoxic period and those sampled two decades later (2004-2008). This seems to confirm temporal changes in the polychaete assemblages possibly due to recovery from anoxia. Also in another area of the NA, Stachowitsch and Fuchs (1995) observed that the recovery of the macrobenthic community after the mass mortality is not reached even ten years after the anoxic event, suggesting that dramatic events might influence assemblages for decades.

PERMANOVA tests confirmed the high spatial-temporal variation as a proper characteristic of the analyzed polychaete assemblages. The main results of differences in assemblages between periods were consistent whatever the considered taxonomic level. However, the describing efficiency of surrogates showed differences concerning the capability to properly describe the assemblages' intrinsic variability. This should not be underrated due to the importance of variability in describing the analyzed assemblages.

Particularly, when untransformed data were considered, the use of families and orders as species surrogates led to misinterpreting the sources of assemblage variation and to noticeable decreasing the estimate of the total variation thus allowing considering the two period and the three stations more similar to each other that they really are. In general, it might be expected that using TS (i.e. a lesser number of variables) leads to reduce the explicated variability, but this "averaging effect" (De Biasi et al., 2003; Doak et al., 1998) is not necessarily the rule (see Tataranni et al., 2009). The question is to determine the extent to which this reduction is acceptable, that is, the amount of variability that can be lost without loosing the capability to highlight differences among assemblages. If the pattern of community change is marked, interpretable results are possible independent of both the examined component of the benthos and the taxonomic level at which the analyses are carried out (Somerfield and Clarke, 1995). Anyway, evidences suggest that using TS might cause a significant loss of information when differences among assemblages are not robust enough (Musco et al., 2009). The decrease of explicated variability might also result from not concordant distribution patterns of taxonomically related species that show differential response to the stressor (Musco et al., 2009). Several co-familial species showed opposite abundance patterns between the two periods (see 3.2, results of SIMPER). The loss of information observed in the 
MDS plots based on family and order taxonomic ranks should be carefully considered. The presence of dominant species belonging to the same genus (or family in this case) showing different responses to a perturbation is considered one of the most important factor limiting the efficiency of the TS method (Dauvin et al., 2003).

Interestingly, weak data transformation was sufficient to allow perfect correspondence in the estimate of variance components among species and taxonomic surrogates. This clearly indicates that abundance is a key factor characterizing the polychaete assemblages. The importance of abundance was further confirmed by the $2^{\text {nd }}$ stage MDS plot, which however indicated that the similarity among matrices rapidly declined after data transformations, independently from the analyzed taxonomic level. This also recommends care in the choice of data transformations.

This study indicates that untransformed data at family level (the most common taxonomic surrogate in environmental monitoring) may represent appropriate assemblages' descriptors in long-term monitoring studies (Bevilacqua et al., 2010; Lasiak, 2003; Olsgard et al., 1998; WlodarskaKuwalczuk and Kedra, 2007). Our results are in accordance with Bevilacqua et al. (2009) suggesting that, in the absence of previous acknowledgements, untransformed data should be analyzed, since it is often difficult to recognize a priori how environmental variations will affect assemblages' structure (e.g., influencing rare or abundant species).

Our data also suggest that, before applying TS and perform approximations of the faunal features of an area, the species-level information should be achieved (Fraser et al., 2006; Gage, 2001; Musco et al., 2009; Olsgard and Somerfield, 2000; Terlizzi et al., 2003). Moreover, as argued by Tataranni et al. (2009), our data support that periodical analysis at fine taxonomic level should be alternated to long-term routine monitoring based on TS, since shifts in dominance between taxonomically related species may occur gradually, altering competitive interactions. This would be particularly alarming if changes in species dominance result from events that are detected only by analyses at the finest taxonomic level, such as alien invasions (see Zenetos et al., 2008) or meridionalization of the NA fauna (Bianchi, 2007; Boero et al., 2008; Mikac and Musco, 2010; Musco and Giangrande, 2005). Changes in community composition over the long trend make up the history of ecosystems and are inherently "unpredictable" (Boero, 1996, 2009, see also Doak et al., 2008). Programming environmental long-term monitoring exclusively based on TS implicitly "predicts" families (higher taxa) as locally fixed unchangeable entities, but this prevents from appreciating important changes within the families, or even genera. For instance, among the worst invasive algae of the Mediterranean, Caulerpa racemosa and C. taxifolia, rank among the 100 worst aliens (Streftaris and Zenetos, 2006), but their presence would pass unnoticed if the genus Caulerpa (represented in the Mediterranean by the common $C$. prolifera) would not be investigated at the species level. The case 
of the genus Caulerpa shows that systems evolve (i.e. change) in time and TS is clearly a not good tool to detect this change.

\section{Acknowledgements}

Thanks to Nando Boero for invaluable comments. The results of this investigation as well as the work of BM were carried out within the projects "Mechanisms of long-term changes in the Adriatic Sea ecosystem" (project no. 0098111) and "Biodiversity of benthic communities in the Adriatic: natural and human impacts" (project no. 098-0982705-2732) both funded by the Ministry of Science, Education and Sports of the Republic of Croatia. The work of LM, AT and AG has been carried out within the MARBEF Network of Excellence which is funded in the Community's Sixth Framework Programme (Contract no. GOCE-CT-2003-505446), the E.U. Integrated Project SESAME and the CMCC (Centro Euro-Mediterraneo per i Cambiamenti Climatici).

\section{References}

Anderson, M.J., 2001. A new method for non-parametric multivariate analysis of variance. Australian Journal of Ecology 26, 32-46.

Anderson, M.J., Gorley, R.N., Clarke, K.R., 2008. PERMANOVA+ for PRIMER: Guide to Software and Statistical Methods. PRIMER-E, Plymouth, UK.

Balmford, A., Green, M.J.B., Murray, M.G., 1996. Using higher taxon richness as a surrogate for species richness: I. Regional tests. Proceedings of the Royal Society of London Series-B Biological Sciences 263, 1267-1274.

Bates, C.R., Scott, G., Tobin, M., Thompson, R., 2007. Weighing the costs and benefits of reduced sampling resolution in biomonitoring studies: perspectives from the temperate rocky intertidal. Biological Conservation. 137, 617-625.

Benedetti Cecchi, L., 2001. Beyond BACI: optimization of environmental sampling designs through monitoring and simulation. Ecological Applications 11, 783-799.

Bertasi, F., Colangelo, M.A., Colosio, F., Gregorio, G., Abbiati, M., Ceccherelli, V.U., 2009. Comparing efficacy of different taxonomic resolutions and surrogates in detecting changes in soft bottom assemblages due to coastal defence structures. Marine Pollution Bulletin 58, 686694.

Bertrand, Y., Pleijel, F., Rouse, G.W., 2006. Taxonomic surrogacy in biodiversity assessments, and the meaning of Linnaean ranks. Systematics and Biodiversity 4, 149-159. 
Bevilacqua, S., Fraschetti, S., Musco, L., Terlizzi, A., 2009. Taxonomic sufficiency in the detection of natural and human-induced changes in marine assemblages: habitats and taxonomic groups compared. Marine Pollution Bulletin 58, 1850-1859.

Bevilacqua, S., Fraschetti, S., Musco, L., Guarnieri, G., Terlizzi, A., 2010 (In press). Low sensitiveness of taxonomic distinctness indices to human impacts: Evidences across marine benthic organisms and habitat types. Ecological Indicators, doi:10.1016/j.ecolind.2010.06.016

Bianchi, C.N., 2007. Biodiversity issues for the forthcoming tropical Mediterranean Sea. Hydrobiologia, 580, 7-21.

Boero, F., 1996. Episodic events: Their relevance to ecology and evolution. Marine Ecology Pubblicazioni della Stazione Zoologica di Napoli I. 17(1-3), 237-250.

Boero, F., 2009. Recent innovations in marine biology. Marine Ecology - An Evolutionary Perspective 30 (Suppl 1), 1-12.

Boero, F., Féral, J.P., Azzurro, E., Cardin, V., Riedel, B., Despalatović, M., Munda, I., Moschella, P., Zaouali, J., Fonda Umani, S., Theocharis, A., Wiltshire, K., Briand, F., 2008. Climate warming and related changes in Mediterranean marine biota. In: F. Briand (ed.) Climate warming and related changes in Mediterranean marine biota, Vol 35, pp. 5-21. CIESM Workshop Monographs, Monaco.

Bowen, R.E., Depledge, M.H., 2006. Rapid Assessment of Marine Pollution (RAMP). Marine Pollution Bulletin 53(10-12), 631-639.

Castelli, A., Lardicci, C., Tagliapietra, D., 2003. Il macrobenthos di fondo molle. In: Gambi, M.C., Dappiano, M., Editors. Manuale di metodologia di campionamento e studio del benthos marino mediterraneo. Biologia Marina Mediterranea 10 (Suppl), 109-144.

Castelli, A., Bianchi, C.N., Cantone, G., Cjnar, M.E., Gambi, M.C., Giangrande, A., Iraci Sareri, D., Lanera, P., Licciano, M., Musco, L., Sanfilippo, R., Simonini, R., 2008. Annelida Polychaeta. In: Relini G, editor. Checklist della flora e della fauna dei mari italiani (Parte I). Biologia Marina Mediterranea, 15(Suppl. 1), 323-373.

Clarke, K.R., Gorley, R.N., 2006. PRIMER V6: user manual/tutorial. PRIMER-E, Plymouth

Dauvin, J.C., Gomez Gesteira, L., Salvande Fraga, M., 2003. Taxonomic sufficiency: an overview of its use in the monitoring of sublittoral benthic communities after oil spills. Marine Pollution Bulletin 46, 552-555.

Dauvin, J.C., Bellan, G., Bellan-Santini, D., 2010. Benthic indicators: From subjectivity to objectivity - Where is the line? Marine Pollution Bulletin 60, 947-953. 
De Biasi, A.M., Bianchi, C.N., Morri, C., 2003. Analysis of macrobenthic communities at different taxonomic levels: an example from an estuarine environment in the Ligurian Sea NW Mediterranean. Estuarine and Coastal Shelf Science 58, 99-106.

Degobbis, D., Precali, R., Ivancic, I., Smodlaka, N., Fuks, D., Kveder, S., 2000. Long-term changes in the northern Adriatic ecosystem related to anthropogenic eutrophication. International Journal of Environment and Pollution 13(1-6), 495-533.

Dethier, M.N., Schoch, G.C., 2006. Taxonomic sufficiency in distinguishing natural spatial patterns on an estuarine shoreline. Marine Ecology Progress Series 306, 41-49.

Doak, D.F., Bigger, D., Harding, E.K., Marvier, M.A., Omalley, R.E., Thomson, D., 1998. The statistical inevitability of stability-diversity relationships in community ecology. American Naturalist 151, 264-276.

Doak, D.F., Estes, J.A., Halpern, B.S., Jacob, U., Lindberg, D.R., Lovvorn, J., Monson, D.H., Tinker, M.T., Williams, T.M., Wootton, J.T., Carroll, I., Emmerson, M., Micheli, F., Novak, M., 2008. Understanding and predicting ecological dynamics: Are major surprises inevitable? Ecology 89(4), 952-961.

Ellis, D., 1985. Taxonomic sufficiency in pollution assessment. Marine Pollution Bulletin 16, 459.

Fraser, C., Hutchings, P., Williamson, J., 2006. Long-term changes in polychaete assemblages of Botany Bay (NSW, Australia) following a dredging event. Marine Pollution Bulletin 52, 9971010.

Fraschetti, S., Gambi, C., Giangrande, A., Musco, L., Terlizzi, A., Danovaro, R., 2006. Structural and functional response of meiofauna rocky assemblages exposed to sewage pollution. Marine Pollution Bulletin 52, 540-548.

Gage, J.D., 2001. Deep-sea benthic community and environmental impact assessment at the Atlantic Frontier. Continental Shelf Research 21, 957-986

Giangrande, A., Delos, A.L., Musco, L., Licciano, M., Pierri, C., 2004. Polychaete assemblages of rocky shore along the South Adriatic coast (Mediterranean Sea). Cahiers de Biologie Marine 45, $85-95$

Giangrande, A., Licciano, M., Musco, L., 2005. Polychaetes as environmental indicators revisited. Marine Pollution Bulletin 50, 1153-1162

Herman, P.M.J., Heip, C., 1988. On the use of meiofauna in ecological monitoring: who needs taxonomy? Marine Pollution Bulletin 19, 665-668.

Kroncke, I., 1995. Long-term changes in North Sea benthos. Senckenbergiana Maritima 26, 73-80.

Lasiak, T., 2003. Influence of taxonomic resolution, biological attributes and data transformations on multivariate comparisons of rocky macrofaunal assemblages. Marine Ecology Progress Series 
250, 29-34.

Mikac, B., Musco L., 2010. Faunal and biogeographic analysis of Syllidae (Polychaeta) from Rovinj (Croatia, northern Adriatic Sea). Scientia Marina 74(2), 353-370.

Munari, C., Tessari, U., Rossi, R., Mistri, M., 2010. The ecological status of Karavasta Lagoon (Albania): Closing the stable door before the horse has bolted? Marine Environmental Research 69(1), 10-17.

Musco, L., Giangrande, A., 2005. Mediterranean Syllidae (Annelida: Polychaeta) revisited: species diversity, biogeography and faunal fidelity to environmental features. Marine Ecology Progress Series 304, 143-153.

Musco, L., Terlizzi, A., Licciano, M., Giangrande, A., 2009. Taxonomic structure and the effectiveness of surrogates in environmental monitoring: a lesson from polychaetes. Marine Ecology Progress Series 383, 199-210.

Olsgard, F., Somerfield, P.J., 2000. Surrogates in benthic investigations. Which taxonomic unit to target? Journal of Aquatic Ecosystem Stress and Recovery 7, 25-42.

Olsgard, F., Somerfield, P.J., Carr, M.R., 1998. Relationship between taxonomic resolution, macrobenthic community patterns and disturbance. Marine Ecology Progress Series 127, 25-36.

Quijón, P.A., Snelgrove, P.V.R., 2006. The use of coarser taxonomic resolution in studies of predation on marine sedimentary fauna. Journal of Experimental Marine Biology and Ecology 330, 159-168.

Schirosi, R., Musco, L., Giangrande, A., 2010. Benthic assemblages of Acquatina Lake (South Adriatic Sea): present state and long-term faunistic changes. Scientia Marina 74(2), 235-246.

Searle, S.R., Casella, G., McCulloch, C.E., 1992. Variance Components. Wiley, NewYork.

Somerfield, P.J., Clarke, K.R., 1995. Taxonomic levels, in marine community studies, revisited. Marine Ecology Progress Series 127, 113-119

Stachowitsch, M., Fuchs, A., 1995. Long-term changes in the benthos of the Northern Adriatic Sea. Annales 7, 7-16

Streftaris, N., Zenetos, A., 2006. Alien Marine Species in the Mediterranean - the 100 'Worst Invasives' and their Impact. Mediterranean Marine Science 7(1), 87-118.

Tataranni, M., Maltagliati, F., Floris, A., Castelli, A., Lardicci, C., 2009. Variance estimate and taxonomic resolution: An analysis of macrobenthic spatial patterns at different scales in a Western Mediterranean coastal lagoon. Marine Environmental Research 67, 219-229.

Terlizzi, A., Bevilacqua, S., Fraschetti, S., Boero, F., 2003. Taxonomic sufficiency and the increasing insufficiency of taxonomic expertise. Marine Pollution Bulletin 46, 556-561. 
Terlizzi, A., Anderson, M.J., Fraschetti, S., Benedetti Cecchi, L., 2007. Scales of spatial variation in Mediterranean subtidal sessile assemblages at different depths. Marine Ecology Progress Series $332,25-39$.

Terlizzi, A., Anderson, M.J., Bevilacqua, S., Fraschetti, S., Wlodarska-Kowalczuk, M., Ellingsen, K.E., 2009. Beta diversity and taxonomic sufficiency: Do higher-level taxa reflect heterogeneity in species composition. Diversity and Distributions 15(3), 450-458.

Thompson, B.W., Riddle, M.J., Stark, J.S., 2003. Cost-efficient methods for marine pollution monitoring at Casey Station, east Antarctica: the choice of sieve meshsize and taxonomic resolution. Marine Pollution Bulletin 46, 232-243.

Ugland, K.I., Bjørgesæter, A., Bakke, T., Fredheim, B., Gray, J.S., 2008. Assessment of environmental stress with a biological index based on opportunistic species. Journal of Experimental Marine Biology and Ecology 366(1-2), 169-174.

Underwood, A.J., 1996. Detection, interpretation, prediction and management of environmental disturbances: some roles for experimental marine ecology. Journal of Experimental Marine Biology and Ecology 200, 1-27.

Underwood, A.J., Peterson, C.H., 1988. Towards an ecological framework for investigating pollution. Marine Ecology Progress Series 46, 227-234.

Vanderklift, M.A., Ward, T.J., Jacoby, C.A., 1996. Effect of reducing taxonomic resolution on ordinations to detect pollution-induced gradients in macrobenthic infaunal assemblages. Marine Ecology Progress Series 136, 137-145.

Warwick, R.M., 1988. The level of taxonomic discrimination required to detect pollution effects on marine benthic communities. Marine Pollution Bulletin 19, 259-268.

Wlodarska-Kowalczuk, M., Kedra, M., 2007. Surrogacy in natural patterns of benthic distribution and diversity: selected taxa versus lower taxonomic resolution. Marine Ecology Progress Series $351,53-63$

Zenetos, A., Meric, E., Verlaque, M., Galli, P., Boudouresque, C.F., Giangrande, A., Çinar, M.E., Bilecenoglu, M., 2008. Additions to the annotated list of marine alien biota in the Mediterranean with special emphasis on Foraminifera and Parasites. Mediterranean Marine Science 9(1), 119165. 


\section{$1 \quad$ Figure Captions}

2

3 Figure 1. Study area and position of the three investigated stations

4

5 Figure 2. Univariate indices of polychaete assemblages at each station for both periods during the

6 different sampling times. Mean temporal values calculated for each station were also showed as a

7 line

8

9 Figure 3. non-metric MDS ordinations of polychaete assemblages based on Bray-Curtis similarity of untransformed data at species (a), genus (b), family (c) and order (d) taxonomic level of 11 identification

Figure 4. Estimates of variance components for each source of variation as obtained by PERMANOVA analyses performed at all investigated taxonomic levels, with different transformations: no transformation (a), square root (b), fourth root (c) and presence/absence (d). The variability of each term was expressed as a proportion of the total variation

Figure 5. 'second stage' MDS ordination of resemblance matrices derived from species (S), genus (G), family (F) and order (O) untransformed abundance data and several transformations (2rt: square root; 4rt: fourth root; PA: presence/absence) 
Research highlights

- Polychaetes families detect decadal changes in the multivariate assemblages structure

- TS and data transformation may underrate patterns of spatial assemblages variability

- TS-based long-term monitoring must include periodical fine taxonomic analyses 
Table 1. Results of ANOVA analyses for number of individuals, species richness and Simpson diversity testing for differences in polychaete assemblages. $\mathrm{P}=$ period; St = station; $\mathrm{T}=$ time. Significant $\mathrm{P}$-values are given in italics.

\begin{tabular}{|c|c|c|c|c|c|c|c|c|c|c|}
\hline \multirow[b]{2}{*}{ Source } & \multirow[b]{2}{*}{ df } & \multicolumn{3}{|c|}{ Number of individuals } & \multicolumn{3}{|c|}{ Species richness } & \multicolumn{3}{|c|}{ Simpson diversity } \\
\hline & & MS & $\mathrm{F}$ & $\mathrm{P}$ & MS & $\mathrm{F}$ & $\mathrm{P}$ & MS & $\mathrm{F}$ & $\mathrm{P}$ \\
\hline $\mathrm{Pe}$ & 1 & 12687 & 2.66 & 0.111 & 228.78 & 1.83 & 0.214 & 0.1751 & 5.27 & 0.030 \\
\hline St & 2 & 1112.3 & 1.06 & 0.395 & 163.05 & 11.07 & 0.002 & 0.0219 & 7.52 & 0.005 \\
\hline $\mathrm{T}(\mathrm{Pe})$ & 7 & 2929.9 & 2.74 & 0.046 & 86.01 & 5.86 & 0.003 & 0.0281 & 9.70 & 0.001 \\
\hline $\mathrm{Pe} \times \mathrm{St}$ & 2 & 2299.7 & 2.19 & 0.136 & 49.031 & 3.33 & 0.067 & 0.0063 & 2.16 & 0.166 \\
\hline $\mathrm{T}(\mathrm{Pe}) \times \mathrm{St}$ & 14 & 1069.2 & 3.49 & 0.001 & 14.665 & 0.85 & 0.630 & 0.0029 & 0.95 & 0.530 \\
\hline Res & 86 & 306.47 & & & 17.344 & & & 0.0031 & & \\
\hline
\end{tabular}


Table 2. Results of SIMPER analysis. Average abundance (Av. Abund.) and percentage contribution (Contrib. \%) to the average dissimilarity between periods for species reaching the cumulative contribution of $70 \%$ are reported. Species are divided in relation to the family and order taxonomical levels, which are listed alphabetically

\begin{tabular}{|c|c|c|c|c|c|}
\hline \multirow[b]{2}{*}{ Order } & \multirow[b]{2}{*}{ Family } & \multirow[b]{2}{*}{ Species } & \multirow{2}{*}{$\begin{array}{l}\text { Period } 1 \\
\text { Av. Abund }\end{array}$} & \multicolumn{2}{|l|}{ Period 2} \\
\hline & & & & Av. Abund & Contrib\% \\
\hline Capitellida & Capitellidae & Notomastus latericeus & 2.43 & 4.11 & 4.92 \\
\hline \multirow[t]{5}{*}{ Eunicida } & Eunicidae & Eunice vittata & 8.19 & 0.77 & 7.99 \\
\hline & Lumbrineridae & Lumbrineris latreilli & 1.51 & 0 & 2.06 \\
\hline & Onuphidae & Nothria conchilega & 6.28 & 0.09 & 6.35 \\
\hline & & Aponuphis grubii & 0 & 1.2 & 1.51 \\
\hline & & Aponuphis brementi & 0.96 & 0.73 & 1.4 \\
\hline \multirow[t]{2}{*}{ Flabelligerida } & Flabelligeridae & Pherusa plumosa & 0.96 & 0.05 & 1.18 \\
\hline & & Piromis eruca & 0.85 & 0.03 & 1 \\
\hline \multirow[t]{2}{*}{ Oweniida } & Oweniidae & Owenia fusiformis & 13.26 & 4.42 & 12.99 \\
\hline & & Galathowenia oculata & 0.38 & 2.73 & 3.46 \\
\hline Phyllodocida & Glyceridae & Glycera unicornis & 1.04 & 0.74 & 1.5 \\
\hline Sabellida & Serpulidae & Pomatoceros triqueter & 0.23 & 0.89 & 1.27 \\
\hline \multirow[t]{2}{*}{ Spionida } & Spionidae & Polydora ciliata & 1.68 & 0 & 1.82 \\
\hline & & Spiophanes kroyeri & 0 & 1.21 & 1.66 \\
\hline Sternaspida & Sternaspidae & Sternaspis scutata & 0.23 & 1.3 & 1.72 \\
\hline \multirow[t]{5}{*}{ Terebellida } & Ampharetidae & Ampharete acutifrons & 0 & 4.2 & 5.34 \\
\hline & & Amphicteis gunneri & 2.47 & 0.2 & 2.75 \\
\hline & Pectinariic & Pectinaria auricoma & 9.66 & 4.03 & 9.15 \\
\hline & & Pectinaria koreni & 0.96 & 0.38 & 1.44 \\
\hline & Trichobranchida & Terebellides stroemi & 0.11 & 1.09 & 1.43 \\
\hline
\end{tabular}


Table 3. PERMANOVA analyses based on the Bray-Curtis dissimilarity for untransformed abundance data at species (173 variables), genera (115), family (35) and order (14) taxonomic level. The analyses were carried out using 999 permutations of residuals under a reduced model. Estimates of variance components (VC) for each analysed source of variation were also included. $\mathrm{P}=$ period; $\mathrm{St}=$ station; $\mathrm{T}=$ time

\begin{tabular}{llllllllll}
\multicolumn{9}{c}{ Species } & \multicolumn{7}{c}{ Genera } \\
Source & df & MS & F & P(perm) & VC & MS & F & P(perm) VC \\
Pe & 1 & 56099 & 3.81 & 0.006 & 798.78 & 54286 & 3.98 & 0.007 & 783.09 \\
$\mathrm{St}$ & 2 & 11372 & 3.98 & 0.001 & 234.55 & 11143 & 4.21 & 0.001 & 234.02 \\
$\mathrm{~T}(\mathrm{Pe})$ & 7 & 6965.8 & 2.41 & 0.001 & 325.09 & 6644.1 & 2.48 & 0.001 & 316.35 \\
$\mathrm{Pe} \times \mathrm{St}$ & 2 & 8643.2 & 3.02 & 0.001 & 318.75 & 7791.2 & 2.94 & 0.001 & 283.36 \\
$\mathrm{~T}(\mathrm{Pe}) \times \mathrm{St}$ & 14 & 2893.4 & 2.07 & 0.001 & 358.36 & 2681.2 & 2.08 & 0.001 & 333.44 \\
$\mathrm{Res}$ & 86 & 1395.5 & & & 1395. & 1287.4 & & & 1287.4 \\
Tot & 112 & & & & 3431.03 & & & & 3237.66
\end{tabular}

\begin{tabular}{|c|c|c|c|c|c|c|c|c|c|}
\hline \multirow[b]{2}{*}{ Source } & \multirow[b]{2}{*}{ df } & \multicolumn{4}{|c|}{ Families } & \multicolumn{4}{|l|}{ Orders } \\
\hline & & MS & $\mathrm{F}$ & $\mathrm{P}($ perm $)$ & $\mathrm{VC}$ & MS & $\mathrm{F}$ & $\mathrm{P}($ perm $)$ & $\mathrm{VC}$ \\
\hline $\mathrm{Pe}$ & 1 & 25183 & 2.23 & 0.031 & 278.61 & 15721 & 2.06 & 0.039 & 164.61 \\
\hline St & 2 & 9606.8 & 4.13 & 0.001 & 200.61 & 6880.3 & 4.12 & 0.001 & 143.51 \\
\hline $\mathrm{T}(\mathrm{Pe})$ & 7 & 6019.1 & 2.55 & 0.001 & 292.32 & 3490 & 2.06 & 0.002 & 143.09 \\
\hline $\mathrm{P} \times \mathrm{St}$ & 2 & 6440.4 & 2.77 & 0.001 & 226.74 & 5009.8 & 2.99 & 0.002 & 183.95 \\
\hline $\mathrm{T}(\mathrm{Pe}) \times \mathrm{St}$ & 14 & 2357.2 & 2.37 & 0.001 & 325.69 & 1697.8 & 3.02 & 0.001 & 271.64 \\
\hline Res & 86 & 995.83 & & & 995.83 & 562.38 & & & 562.38 \\
\hline Tot & 112 & & & & 2319.08 & & & & 1469.18 \\
\hline
\end{tabular}




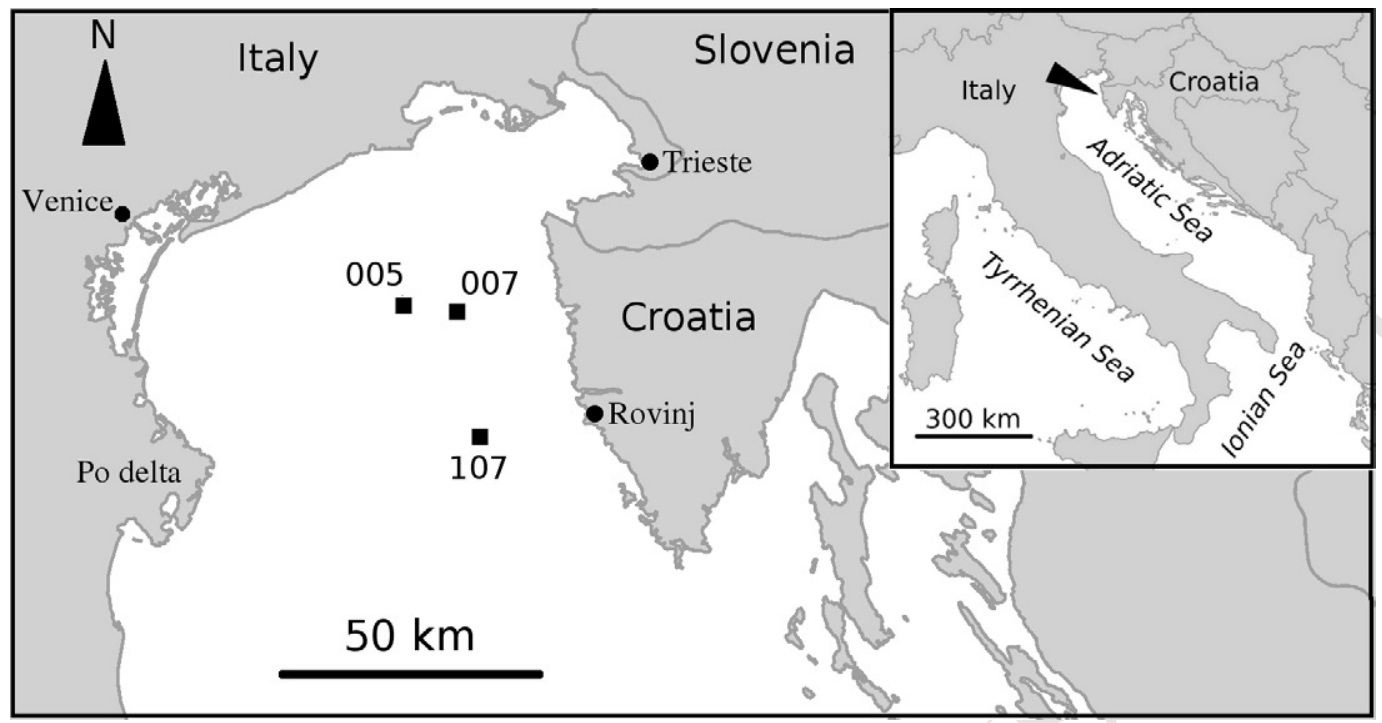



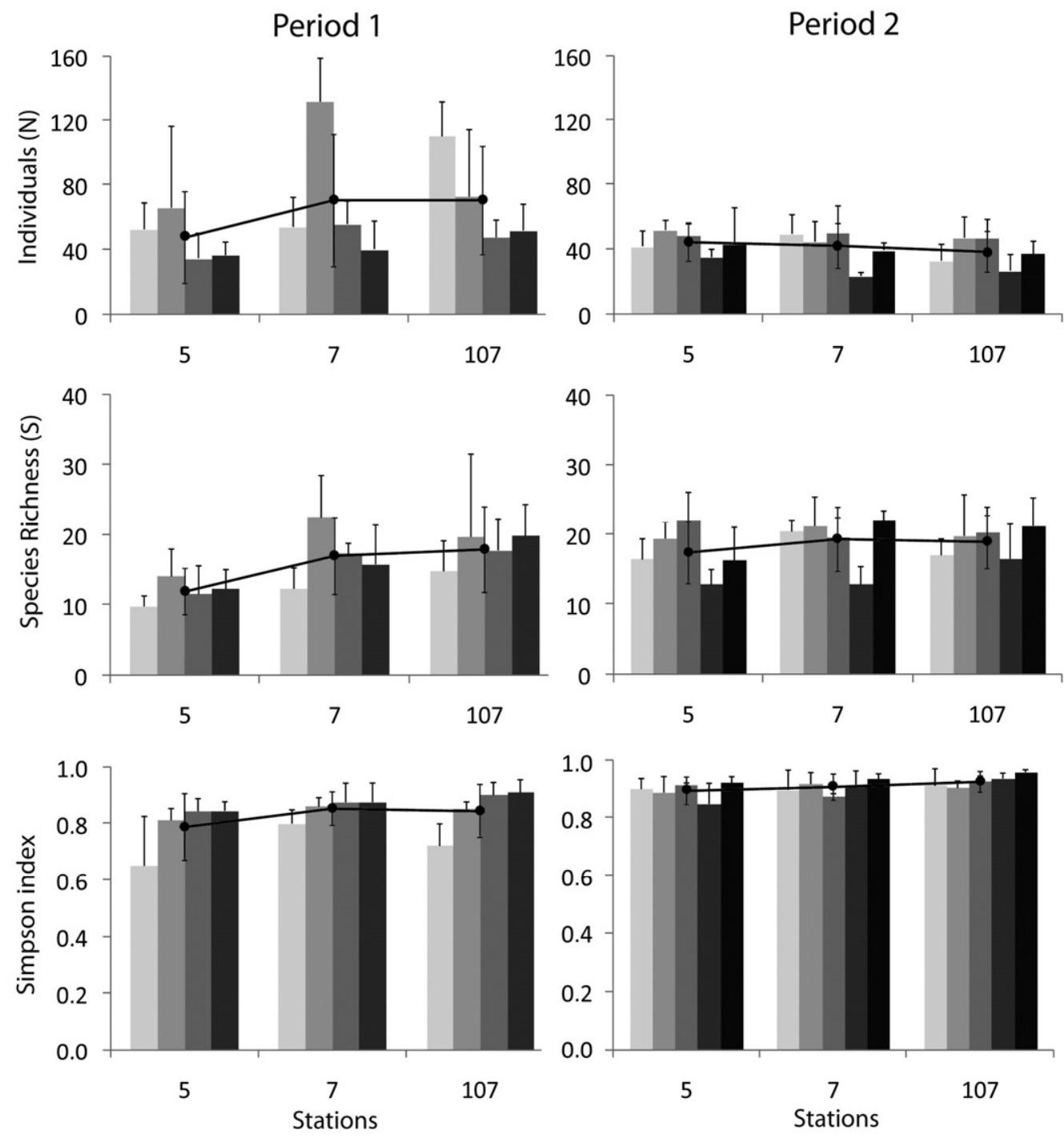

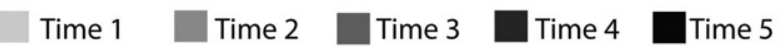



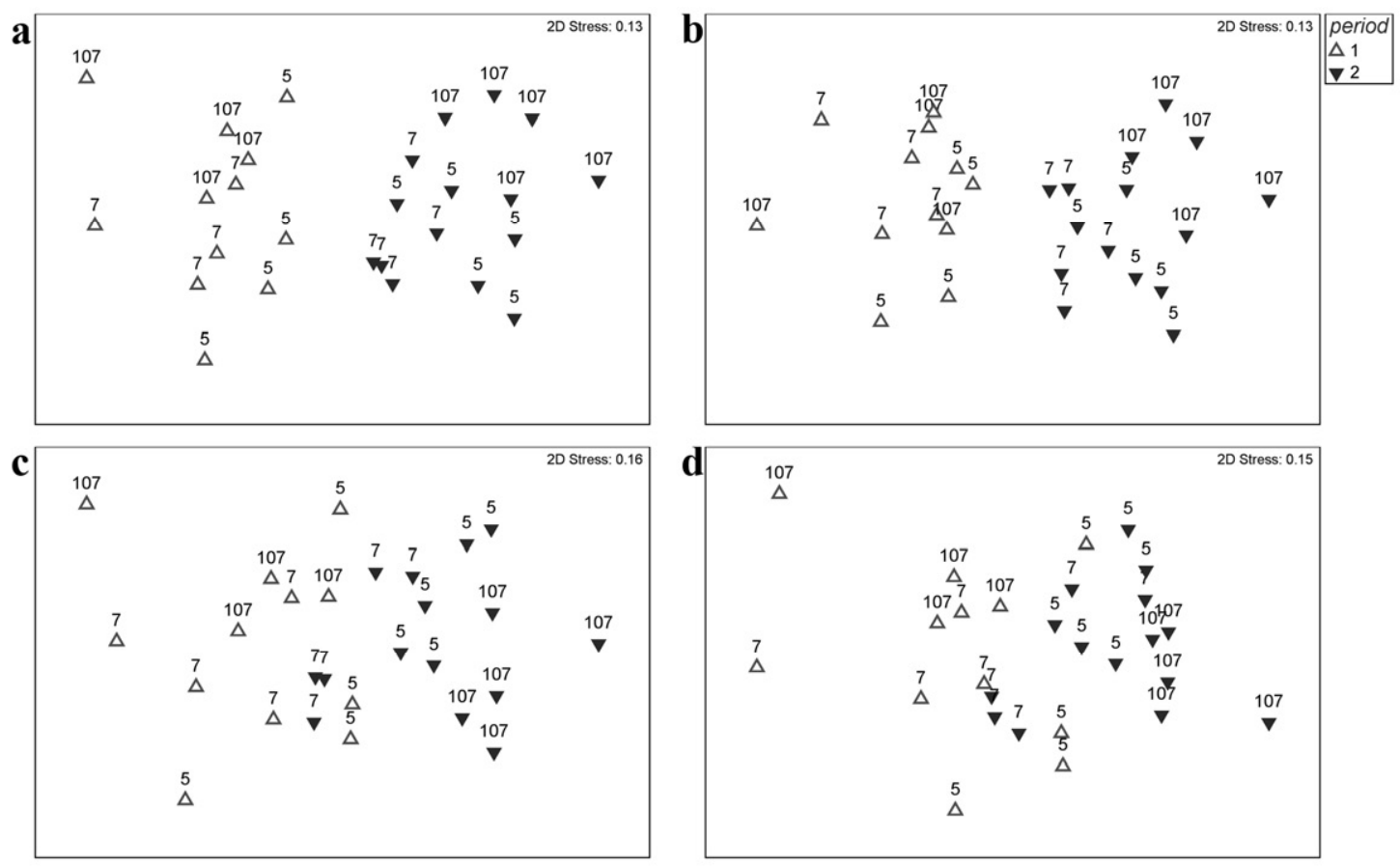

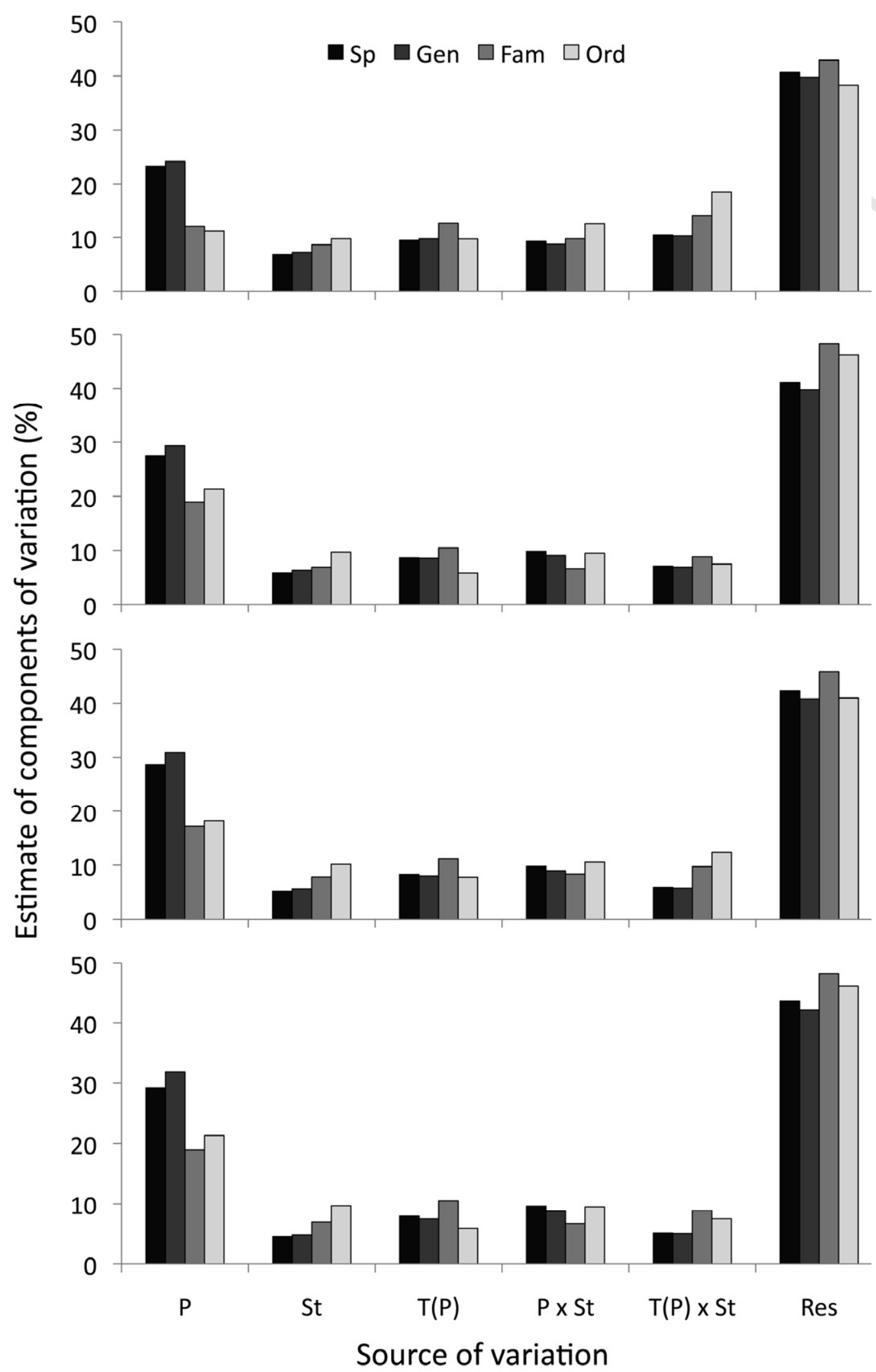


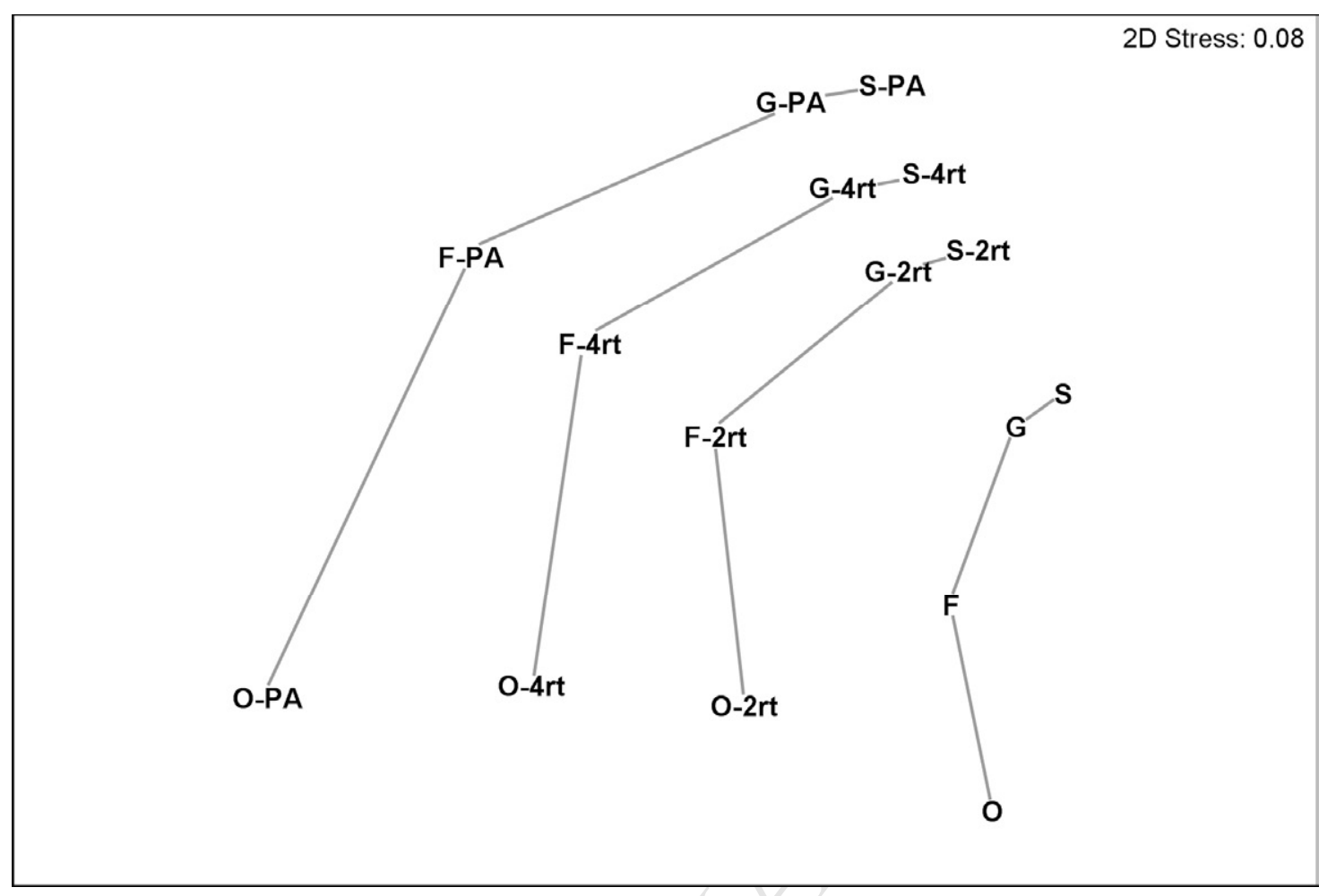

